\title{
The management of glaucoma and intraocular hypertension: current approaches and recent advances
}

\author{
Robert J Noecker \\ University of Pittsburgh Medical \\ Center, Eye and Ear Institute, \\ Pittsburgh, PA, USA
}

\begin{abstract}
In the last decade, numerous novel ocular hypotensive agents have been introduced for the control of intraocular pressure (IOP). Clinicians now have more options than ever in the selection of medical therapy for the treatment of glaucoma and ocular hypertension. When selecting an ocular hypotensive medication for their patients, clinicians should consider not only the IOP-lowering efficacy of an agent, but also the ability of the drug to allow patients to achieve target levels of IOP that are low enough to stop the progression of glaucomatous damage. Other considerations should include how well the drug controls diurnal IOP, the likelihood of serious adverse events, the versatility of the medication for use as an adjunctive agent, as well as other potential attributes (ie, neuroprotection).
\end{abstract}

Keywords: glaucoma, ocular hypertension, intraocular pressure, target pressure

\section{Introduction}

Glaucoma is the second leading cause of blindness worldwide (Thylefors and Négrel 1994). It is now recognized as the leading cause of blindness among African Americans in the US (Quigley and Vitale 1997) and data from 6357 participants in the Los Angeles Latino Eye Study suggest that the prevalence of open-angle glaucoma (OAG) is higher among Latinos of Mexican ancestry than in the Caucasian population (Varma et al 2004). It is estimated that more than 4 million people in the US have glaucoma; 130000 of these individuals are legally blind from the disease. In addition, another 5-10 million individuals may have elevated IOP (Quigley and Vitale 1997; EDGED 2002). Risk factors for glaucoma include advanced age, African ancestry, a family history of glaucoma, severe myopia, and ocular risk factors, such as higher intraocular pressure (IOP), morphologic features of the optic disc, and thinness of the cornea (Gordon et al 2002; Kass et al 2002; Kroese and Burton 2003; Jonas et al 2004; Martus et al 2005).

Although elevated IOP is one of the most consistent risk factors for the development or progression of glaucoma, it is no longer considered a defining characteristic. Instead, it is now clear that the glaucomas are actually a group of chronically progressive neuropathies characterized by atrophy of the optic nerve, visual field deficits due to the loss of retinal ganglion cells (RGC), and cupping of the optic nerve head (AAO 2000). Glaucoma has few subjective symptoms during a long period early in the disease, but damage is irreversible once it occurs. Early detection of progression and treatment are critical to limit this damage.

The established treatment paradigm for OAG and ocular hypertension (OHT) (which is characterized by an IOP $>21 \mathrm{~mm} \mathrm{Hg}$ and lack of any glaucomatous changes of the optic disc or visual field defects) has long concentrated on lowering IOP to a level at which the progression (or onset) of glaucomatous damage is halted or delayed. 
In recent years, however, the treatment paradigm has become considerably more aggressive. This change is due both to the availability of more powerful ocular hypotensive agents as well as to the increased understanding of the need to achieve the lowest possible pressures to preserve the visual field. Whereas successful glaucoma therapy was once defined as an IOP reduced (with treatment) to within two standard deviations of the mean of a normal population, clinicians today see halting the progression of glaucomatous damage and preserving the visual field of each patient as the only acceptable treatment outcome.

Ophthalmologists are presently faced with a myriad of choices for ocular hypotensive therapy. The medications available for reducing IOP in glaucoma patients include topical $\beta$-adrenergic antagonists (eg, timolol, betaxolol), carbonic anhydrase inhibitors (eg, dorzolamide, brinzolamide), cholinergics (eg, pilocarpine), $\alpha$-adrenergic agonists (eg, brimonidine), prostaglandins (eg, latanoprost, travoprost), and prostamides (bimatoprost). Fixed combinations of commonly used drugs have also been developed (eg, timolol-dorzolamide and brimonidinetimolol) and may offer benefits of convenience, cost, and safety, but limit individualization of dosing (Fechtner and Realini 2004). The purpose of this review is to provide an overview of clinical efficacy, mechanism of action, safety and tolerability profile, convenience and compliance, and the potential for any added benefits (eg, enhancement of ocular blood flow, neuroprotection) of frequently used glaucoma medications.

\section{Selecting an ocular hypotensive agent}

The selection of an ocular hypotensive agent should include not only an evaluation of IOP-lowering efficacy, but also the level of risk as associated with potential side effects and complications, the mechanism of action of the drug, patient convenience and compliance, and the possibility for added potential benefits (such as enhancement of ocular blood flow or neuroprotection).

Safety and tolerability is of utmost concern when selecting any ocular hypotensive agent for chronic use. Ocular and systemic side effects of topical ocular medications must be identified, especially those that seriously affect systemic health and patient quality of life. Every drug has side effects and the risk of those side effects must be balanced with the potential benefits arising from lowering IOP.

Consideration of the mechanism of action of an ocular hypotensive medication may allow for optimal treatment outcomes, especially when selecting agents for adjunctive use. This is important because most classes of medications lower IOP by different mechanisms and certain combinations of these agents may maximize efficacy. Specifically, the prostamides, prostaglandin analogs, and parasympathomimetics increase aqueous outflow. Beta-blockers and carbonic anhydrase inhibitors (CAIs) suppress aqueous formation, and $\alpha$-adrenergic agonists lower IOP by both decreasing aqueous production and increasing uveoscleral outflow. Combining a prostamide or prostaglandin with brimonidine, for example, may maximize IOP-lowering by combining complimentary mechanisms of action.

Patient convenience and compliance are also important factors in selecting an ocular hypotensive regimen. Whenever possible, it is preferable to control IOP with a single medication rather than multiple medications, because every medication added to the regimen has side effects, and each added medication increases the costs of treatment. Furthermore, multiple medications may increase the patient's exposure to benzalkonium chloride (BAK), a common preservative in ophthalmic medications packaged in multi-dose containers. Benzalkonium chloride may accumulate in ocular tissues for a lengthy period of time and at high concentrations, promote cell death in a dose-dependent manner (De Saint Jean et al 1999). Patients are more likely to be compliant with their oncea-day monotherapeutic regimen than with multiple medications given in multiple doses (Coons et al 1994; Patel and Spaeth 1995).

Although modern treatment paradigms focus on controlling IOP, the ultimate goal of any therapy for glaucoma is the preservation of the RGCs. Neuronal cell death in glaucoma occurs when the factors promoting cell death overwhelm the factors promoting cell survival. Factors promoting cell death include mechanical trauma, vascular and metabolic insufficiencies, and genetic predisposition. Factors promoting cell survival include neurotrophins, signaling molecules from neighboring cells, and intrinsic survival factors. The goal of neuroprotection is to slow or prevent death of RGCs by shifting the balance back in favor of cell survival. The potential for added benefit, in this case neuroprotection, should be considered when selecting ocular hypotensive therapy. 


\section{Beta-blockers}

Beta-blockers compete with sympathomimetic substances for access to receptors, reducing sympathetic activity via competitive inhibition (Zimmerman 2000). Sympathetic activity is involved in the active secretion of aqueous via formation of norepinephrine- $\beta$ receptor complex, and betablockers effectively lower IOP by decreasing the production of aqueous. Topical beta-blockers are either nonselective or selective, preferentially inhibiting $\beta 1$ adrenoceptors (Hoyng and van Beek 2000).

Nonselective beta-blockers act by inhibiting both $\beta 1$ and $\beta 2$ adrenergic receptors. Examples of nonselective beta-blockers include levobunolol, metipranolol, carteolol, and timolol. As a class, topical nonselective beta-blockers are reasonably well tolerated locally. For example, the most common ocular adverse events associated with timolol therapy include conjunctival hyperemia, burning, stinging, or superficial punctate keratitis (McMahon et al 1979; Van Buskirk 1980; Zimmerman 2000). Most ocular side effects resolve after the medication is discontinued. Conversely, the systemic side effects associated with topical beta-blockers may be more serious. Topical application of beta-blockers can lead to systemic absorption through conjunctiva and lacrimal drainage system. Timolol may cause bradycardia, arrhythmia, and congestive heart failure by blocking the $\beta 1$ adrenoceptors of the heart (McMahon et al 1979; van Buskirk 1980; Hoyng and van Beek 2000). Timolol is contraindicated in patients with pulmonary disease as inhibition of $\beta 2$ receptors in the bronchi and bronchioles results in contraction of smooth muscle of the bronchial tree from unopposed parasympathetic activity, leading to bronchospasm and respiratory obstruction (McMahon et al 1979; Fraunfelder 1980; Nelson et al 1986; Hoyng and van Beek 2000). Further, timolol crosses the bloodbrain barrier and blocks serotonin receptors in the central nervous system and may cause depression, weakness, fatigue, memory loss, and decreased libido and impotence (Zimmerman 2000). Nonselective beta-blockers should be used with caution in patients with diabetes mellitus (Velde and Kaiser 1983). Moreover, topical beta-blockers may decrease plasma high density lipoprotein (HDL) levels (Bartlett 1999). Several reports have demonstrated that the use of topical beta-blockers may negatively impact patients' quality of life by causing exercise intolerance, sexual dysfunction, and respiratory difficulty (Zimmerman 2000; Simmons and Earl 2002).
The potential for interactions with other medications should be considered before prescribing topical betablockers, especially in elderly patients. A recent report by Valuck (2001) found that $30.2 \%-45.7 \%$ of topical betablocker users surveyed had a concurrent prescription for one or more medications used to treat depression, congestive heart failure, or chronic obstructive pulmonary disease. Topical beta-blockers may exacerbate all of these chronic conditions. These findings underscore the importance of a thorough medical review before prescribing topical betablockers. The concomitant administration of systemic and topical beta-blockers may be inadvisable because of the potential for systemic additive effects and reduced ocular hypotensive efficacy (Schuman 2000). Caution must also be used when prescribing a topical beta-blocker to patients using calcium antagonists, catecholamine-depleting drugs, digitalis and calcium antagonists, and quinidine.

Cardio-selective beta-blockers (eg, betaxolol) preferentially inhibit $\beta 1$ adrenoceptors (Zimmerman 2000). The most frequent adverse reaction to betaxolol is stinging upon instillation, which is minimized by an ocular suspension with a similarly effective 2 -fold reduced concentration $(0.25 \%)$. The extent of $\beta 1$-adrenoreceptor occupancy of topically applied betaxolol in the systemic circulation is less than that of the nonselective blockers and $\beta 2$-receptor occupancy is negligible, providing a better safety profile in patients with cardiopulmonary disease (Yarangumeli and Kural 2004). Recent reports have suggested that betaxolol allows, as a result of calcium and sodium channel blocking activities, improvement of retinal perfusion and may prevent neuronal cell death (Osborne et al 1999, 2005).

Betaxolol lowers IOP by decreasing aqueous production, although it has been shown to be less effective than timolol or brimonidine (Serle 1996; Javitt and Goldberg 2000; Nordmann et al 2002). However, there may be a possible added potential benefit to the use of betaxolol for the treatment of high IOP: enhanced ocular blood flow. Interestingly, many studies evaluated the effect of betaxolol on ocular blood flow, but with conflicting results. Turacli et al (1998) reported that ocular hemodynamics and visual function may be improved by long-term use of betaxolol in patients with normal-tension glaucoma (NTG). Similarly, Arend and associates found that betaxolol (as well as levobunolol, and timolol) increased blood velocities in the epipapillary and retinal capillaries, while decreasing atriovenous passage time by approximately $25 \%$ in normal 
subjects (Arend et al 1998). Conversely, Harris and colleagues (2000) reported that, while both betaxolol and dorzolamide lowered IOP, only dorzolamide significantly accelerated arteriovenous passage of fluorescein dye in the inferior temporal quadrant of the retina, as measured by scanning laser ophthalmoscopy. Additional research is needed before a conclusion may be reached regarding the role of ocular blood flow in the treatment of glaucoma.

\section{Topical carbonic anhydrase inhibitors}

The topical CAIs, dorzolamide and brinzolamide, are sulfonamides that lower IOP by reducing aqueous production (Silver 1998) and are most often used as adjunctive therapy to other antiglaucoma agents (Clineschmidt et al 1998; Tsukamoto et al 2005). The CAIs reduce aqueous production less than timolol and lower IOP to a lesser extent (Silver 1998; Wayman et al 1997).

The most commonly reported adverse events with topical CAIs are burning and stinging, bad taste in the mouth, and conjunctivitis. The CAIs may be contraindicated in patients with allergies to sulfa (Zimmerman 2000). The CAIs are most often prescribed in twice daily (BID) or thrice daily (TID) regimens.

\section{Cholinergic agonists}

Parasympathomimetic agents, most commonly pilocarpine, are rarely used as first-line therapy today, but are considered third-line treatment options. When added to bimatoprost at concentrations of $2 \%, 4 \%$, and $6 \%$, pilocarpine was reported to be neither additive nor antagonistic to the ocular hypotensive efficacy of bimatoprost (Toor et al 2005).

\section{$\alpha_{2}$ adrenoceptor agonist}

Brimonidine, a highly selective and potent $\alpha_{2}$ adrenoceptor agonist, lowers IOP by a dual mechanism of action: increasing uveoscleral outflow and decreasing aqueous production (Toris et al 1993). Originally available as brimonidine $0.2 \%$, the first reformulation of brimonidine, brimonidine purite $0.15 \%$, provided a $25 \%$ reduction in active ingredient and a new, gentler preservative, purite. The latest formulation of brimonidine is currently available as Alphagan P $0.1 \%$, providing a 50\% decrease in active ingredient but still providing equivalent IOP lowering to the original $0.2 \%$ solution.

Since its introduction as brimonidine $0.2 \%$ ophthalmic solution, brimonidine has proven in clinical trials to be a safe and effective monotherapy, adjunctive, and replacement therapy for the long-term management of glaucoma and OHT (Schuman et al 1997; Lee 2000; Lee et al 2000). Clinical trials have demonstrated the efficacy of brimonidine as both monotherapy (Serle 1996; Katz 1999) and as a highly efficacious adjunctive agent (Simmons 2001; Simmons and Earl 2002; Hommer et al 2003). Brimonidine has been shown to effectively lower IOP when used as an adjunct to latanoprost. In a comparison of the IOP-lowering efficacy of a dual regimen of brimonidine and latanoprost with the fixed combination of timolol and dorzolamide, the dual regimen of brimonidine and latanoprost provided significantly greater mean IOP reductions than did the fixed combination of timolol/dorzolamide (Zabriskie et al 2000). In a post-hoc analysis of 554 patients who received brimonidine BID as adjunctive therapy to latanoprost, patients achieved an additional 32.2\% (5.9 mm Hg) IOP reduction when brimonidine was added to latanoprost monotherapy $(\mathrm{p}<0.001)$. When brimonidine was added to an ongoing treatment regimen of latanoprost plus one or more ocular hypotensive medications, brimonidine provided additional IOP reductions ranging from 15.5\% $(3.6 \mathrm{~mm} \mathrm{Hg}$, $\mathrm{p}<0.002$ ) to $20.1 \%$ (6.6 mm Hg, $\mathrm{p}<0.001)$ (Lee et al 2000). An earlier post-hoc analysis of this same open-label community study with 554 patients concluded that brimonidine effectively lowered overall mean IOP from baseline when used as monotherapy, combination, or replacement therapy (Lee 2000).

Brimonidine $0.2 \%$ significantly reduced IOP from baseline in 23 patients with uncontrolled primary open angle glaucoma (POAG) when used adjunctively with dorzolamide. Overall mean IOP reduction was $5.6 \pm 1.9 \mathrm{~mm}$ $\mathrm{Hg}$ over a one-year period and was well tolerated by the patients (Ozturk et al 2005). In addition, the additive effect of brimonidine $0.2 \%$ in 40 POAG patients uncontrolled on fixed combination of timolol-dorzolamide was shown to reduce peak/trough IOPs significantly. Brimonidine in combination with timolol-dorzolamide reduced the mean peak/trough IOP by 3.9/2.9 $\mathrm{mm} \mathrm{Hg}$ and 4.6/2.9 $\mathrm{mm} \mathrm{Hg}$ (Akman et al 2005).

The IOP lowering efficacy of brimonidine-purite $0.15 \%$, which contains $25 \%$ less active drug than the $0.2 \%$ formulation, has been shown to be comparable with brimonidine $0.2 \%$ when used as monotherapy in the treatment of glaucoma and OHT (Katz 2002). The preservative in the original formulation, BAK, has been replaced with purite. Benzalkonium chloride, the most common antimicrobial preservative used in topical multiuse ophthalmic preparations, may be more toxic than other 
preservatives at high concentrations (Berdy et al 1992; Pissella et al 2000). It can accumulate and remain in ocular tissue for relatively lengthy periods, and may induce cell death in a dose-dependent manner (Gasset et al 1974; De Saint Jean et al 2000). Patients may be taking multiple glaucoma medications to treat this chronic disease and these patients may be exposed to high concentreations of BAK with potentially detrimental ocular effects (Grant and Schuman 1990; Debbasch et al 2000). Conversely, purite is a stabilized oxychloro complex and oxidative preservative which is converted to natural tear components, sodium and chloride ions, oxygen, and water (Masschelein 1979; Rozen et al 1998). It is a microbicide with a wide spectrum of antimicrobial activity and a very low level of toxicity in mammalian cells (Grant et al 1996). Beyond offering a more gentle preservative, animal studies also suggest that brimonidine tartrate has enhanced ocular bioavailability when formulated with purite (Dong et al 2004) and it has been hypothesized that the similarity of IOP-lowering provided with the smaller amount of active drug may be due to this increased bioavailability due to the near-neutral $\mathrm{pH}$ in the reformulation (Acheampong et al 2002). Brimonidine purite $0.15 \%$ has been shown to have $41 \%$ lower rates of ocular allergy than the original brimonidine (Katz 2002).

The newest member of the brimonidine family, brimonidine Purite ${ }^{\circledR} 0.1 \%$ contains 50\% less active drug than the original $0.2 \%$ formulation while providing equivalent IOP lowering. Brimonidine tartrate ophthalmic solution $0.1 \%$ is indicated for lowering IOP in patients with open-angle glaucoma or OHT. A multicenter, doublemasked, randomized, parallel trial was conducted to compare the IOP lowering efficacy of brimonidine P $0.1 \%$ with brimonidine $0.2 \%$ (Data on file, Allergan, Irvine CA, USA). Patients were 18 years or older with need for bilateral treatment of elevated IOP $\leq 22 \mathrm{~mm} \mathrm{Hg}$ or $\leq 34 \mathrm{~mm} \mathrm{Hg}$ (asymmetry of IOP between eyes of $\leq 5 \mathrm{~mm} \mathrm{Hg}$ ). Patients were stratified into 2 groups based on average IOP of both eyes at baseline $(\leq 25 \mathrm{~mm} \mathrm{Hg}$ or $>25 \mathrm{~mm} \mathrm{Hg}$ ) to ensure equal baseline IOPs. Patients in each group were then randomized with equal allocation into one of two treatment arms. 215 patients were randomized to brimonidine P $0.1 \%$ TID and 218 to brimonidine tartrate $0.2 \%$ TID. Mean change from baseline IOP at each timepoint ranged from $-2.7 \mathrm{~mm} \mathrm{Hg}$ to $-5.4 \mathrm{~mm} \mathrm{Hg}$ with brimonidine P $0.1 \%$ and from $-2.3 \mathrm{~mm}$ $\mathrm{Hg}$ to $-5.3 \mathrm{~mm} \mathrm{Hg}$ with brimonidine tartrate $0.2 \%$. Mean IOP reductions from baseline were statistically significant at each timepoint for both groups $(\mathrm{p}<0.001)$.
In addition to demonstrated efficacy and availability of a preferred preservative, brimonidine may offer the added benefit of neuroprotection. Experimental models have shown brimonidine to have neuroprotective properties (Yoles et al 1999; Wheeler et al 2001, 2003; WoldeMussie et al 2001). In order to be considered a neuroprotective agent for treating glaucoma, four criteria must be met and brimonidine meets three of these four: (1) brimonidine receptors are present in the retina and binding to these receptors activates mechanisms of neuronal survival in animal models (Wheeler et al 2001); (2) the neuroprotective activity of brimonidine has been demonstrated in animal models and supported by cell culture models (Yoles et al 1999; Wheeler et al 2001, 2003; WoldeMussie et al 2001); (3) following clinical dosing, brimonidine achieves concentrations at the retina sufficient to bind to and trigger the $\alpha_{2}$-receptors responsible for neuroprotective activity (Kent et al 2001); (4) neuroprotective activity should be demonstrated in clinical trials. This fourth criterion is currently being evaluated in clinical trials.

Brimonidine has not been shown to exert any clinically significant effects on heart rate or blood pressure. The most commonly-reported adverse event with brimonidine therapy is ocular allergy and associated side effects are reversible upon discontinuation. Studies show that brimonidine $0.2 \%$ has a lower risk of systemic adverse events than topical $\beta$ blockers (Serle 1996; Schuman 1996; Schuman et al 1997; Le Blanc 1998; Javitt and Goldberg 2000) and a lower risk of ocular allergy and shows no cross toxicity compared with apraclonidine (Robin 1995).

\section{Prostaglandins Latanoprost}

Latanoprost is a biologically inactive prodrug of a prostaglandin $\mathrm{F}_{2 \alpha}(\mathrm{PGF} 2 \alpha)$ analogue with selective FP receptor agonist activity that lowers IOP by enhancing uveoscleral outflow (Toris et al 1993).

Latanoprost, a once-daily (QD) drug, is a potent ocular hypotensive agent. Latanoprost has been shown to provide IOP lowering superior to that provided by timolol (Sihota et al 2003, 2004). The mean IOP reduction with latanoprost in long-term studies ( $\geq 6$ months) has typically ranged from 25\% to 34\% (Camras 1996; Mishima et al 1996; Watson and Stjernschanz 1996). A large-scale 3-month clinical trial by Parrish and associates (2003) compared the IOP lowering efficacy of latanoprost with that of bimatoprost and travoprost. There were no significant among-group 
differences in mean IOP reduction in the intent-to-treat population, but bimatoprost consistently lowered IOP to a greater extent than did either latanoprost or timolol. Latanoprost is a versatile drug and has demonstrated efficacy when used as adjunctive therapy to beta-blockers, brimonidine, and cholinergic agonists (Walters et al 2000; Zabriskie et al 2000; Toris et al 2002).

Several studies have demonstrated that a substantial percentage of patients may be nonresponsive to latanoprost therapy. A study by Scherer (2002) reported that approximately $25 \%$ of patients were nonresponsive to latanoprost (defined as a $<20 \%$ reduction in IOP). Further, in an evaluation of the efficacy of latanoprost compared with bimatoprost, $38 \%$ to $50 \%$ of patients failed to achieve an IOP reduction $\geq 20 \%$ after 6 months of latanoprost therapy (Noecker, Dirks, et al 2003).

Latanoprost is generally safe and well tolerated. Mild conjunctival hyperemia has been shown to be the most common adverse event, with an incidence of up to $31 \%$. Hyperpigmentation of the irides has been reported with 312 months of latanoprost therapy and is more common in patients with irides of mixed color (Camras et al 1996; Chiba et al 2003, 2004). Hypertrichosis and hyperpigmentation of the eyelashes is also a relatively common side effect of long-term latanoprost therapy (Johnstone et al 1997; Chiba et al 2004). Serious adverse events associated with latanoprost therapy are rare but include anterior uveitis and cystoid macular edema in susceptible patients (Fechtner et al 1998; Warwar et al 1998). A 5-year, multi-center, clinical trial found latanoprost therapy to be safe and well tolerated (Alm et al 2004). However, several reports have suggested that latanoprost therapy may be associated with reactivation of latent herpes simplex keratitis (Wand et al 1999; Morales et al 2001).

A double-masked, 2-period crossover study in black and white patients showed intraocular pressure after treatment with latanoprost was lower than that after timolol treatment in black patients with primary open-angle glaucoma or OHT. At 1 of 2 timepoints, latanoprost caused a significantly greater reduction of IOP in black patients than in white patients (Kitnarong et al 2004).

\section{Unoprostone isopropyl $0.15 \%$}

Unoprostone isopropyl is a decosanoid that demonstrates weak agonist activity for FP receptors and almost no affinity for EP1 and EP2 receptors (Goh and Kishino 1994; Hoyng and van Beek 2000). Unoprostone lowers IOP primarily by increasing uveoscleral outflow, but may also slightly increase trabecular outflow (Sakurai et al 1993; Taniguchi et al 1996).

The clinical efficacy of unoprostone is reported to be similar to that of timolol but less than that of latanoprost (Azuma et al 1993; Yamamoto et al 1997). The dosing recommendation is BID. Most large-scale evaluations of the efficacy of unoprostone have been conducted in Japan. This homogeneity of patient populations makes it difficult to extrapolate the IOP lowering provided by unoprostone to ethnically diverse populations.

Unoprostone is generally well tolerated with conjunctival hyperemia the most commonly reported adverse event, occurring in $4 \%$ to $12 \%$ of patients. More seriously, corneal erosion has been reported in $3 \%$ to $5 \%$ of patients (Yamamoto et al 1997). The incidence of iridial pigmentation induced by unoprostone is high in the case of long-term treatment (Chiba et al 2003).

Several clinical trials have reported that unoprostone may improve ocular blood flow by decreasing vascular resistance. Further, a possible antagonistic effect between endothelin 1 and unoprostone in the choroidal vasculature has been reported (Polska et al 2002).

\section{Travoprost}

The clinical efficacy of travoprost, a synthetic prostaglandin $\mathrm{F}_{2 \alpha}$-receptor agonist, has been reported in several clinical trials. A 12 -week, open-label study in 1590 patients conducted at 219 sites in Switzerland reported in patients previously treated with a single drug, travoprost decreased IOP to pressures below those achieved on prior therapy. In all groups, travoprost reduced mean IOP below $18 \mathrm{~mm} \mathrm{Hg}$ with 1 month of starting therapy, and control was maintained for at least 3 months (Przydryga et al 2004). A 12-month comparison of travoprost, latanoprost, and timolol reported travoprost to be more effective than timolol and as effective as latanoprost at several time points (Netland et al 2001). Diurnal mean reductions in IOP ranged from $6.6 \mathrm{~mm} \mathrm{Hg}$ to $8.1 \mathrm{~mm} \mathrm{Hg}$ with travoprost. A study by Parrish et al (2003) reported a mean IOP lowering of $8.0 \mathrm{~mm} \mathrm{Hg}$ with travoprost, versus $8.6 \mathrm{~mm} \mathrm{Hg}$ with latanoprost, and $8.7 \mathrm{~mm} \mathrm{Hg}$ with bimatoprost. Travoprost has also been shown to provide additive IOP lowering when used as an adjunct to timolol (Orengo-Nania et al 2001).

A phase III clinical trial comparing travoprost with timolol and latanoprost suggests that travoprost is more 
effective in black patients than in white patients (Netland et al 2001). The mean reduction in IOP from baseline in this study ranged from $6.3 \mathrm{~mm} \mathrm{Hg}$ to $7.9 \mathrm{~mm} \mathrm{Hg}$ in white patients randomized to travoprost $0.004 \%$, compared with mean IOP reductions of $6.9 \mathrm{~mm} \mathrm{Hg}$ to $8.9 \mathrm{~mm} \mathrm{Hg}$ in black patients randomized to the same treatment. At several measurements, travoprost provided significantly lower mean IOP in black patients than either latanoprost or timolol.

Travoprost is prescribed as a QD medication and has been reported to be safe and well tolerated. The most commonly reported adverse event is conjunctival hyperemia (Parrish et al 2003).

\section{Prostamides}

\section{Bimatoprost}

Bimatoprost is a synthetic prostamide analog that lowers IOP by a dual mechanism: primarily by increasing pressuredependent (presumed trabecular meshwork) outflow, but also by increasing pressure-independent (presumed uveoscleral) outflow (Brubaker et al 2001).

Bimatoprost has been shown to control IOP throughout the day, maintaining a flat diurnal curve (Coleman et al 2003; Walters et al 2004; Konstas et al 2005). The pooled 12month results of two trials comparing QD bimatoprost with BID timolol reported that bimatoprost provided significantly greater mean IOP reductions from baseline than timolol at every time of the day and at each study visit, including the 10 AM time point of peak timolol effect (Higginbotham et al 2002). A 12-month extension of these two studies again showed bimatoprost caused significantly greater mean reduction from baseline IOP than timolol at each measurement at each study visit (Cohen et al 2004). Patients were also significantly more likely to achieve low target pressures with bimatoprost than with timol. These results are consistent with earlier trials (Sherwood and Brandt 2001; Brandt et al 2001). These findings also demonstrate that the IOP lowering provided by bimatoprost is sustained with long-term use.

The efficacy of bimatoprost has also been compared with that of latanoprost (Noecker, Dirks, et al 2003). In a 6-month, multi-center, randomized, investigator-masked trial comparing QD bimatoprost with QD latanoprost as monotherapy, more patients achieved low target pressures at all times of the day in the bimatoprost group than the latanoprost group. The target pressure analysis in this study suggests that bimatoprost may reduce the risk of disease progression in more glaucoma and OHT patients than does latanoprost. A decrease in IOP of $15 \%$ to $20 \%$ from baseline is frequently used to define a clinically relevant response to a glaucoma medication (Alm et al 1995; Simmons et al 2000; Nordmann et al 2002) and, in this study, the responder rate at 6 months was statistically significantly higher in the bimatoprost group than the latanoprost group at all times measured regardless of whether a therapeutically relevant response was defined as a $15 \%$ or $20 \%$ IOP decrease. The results of this study were consistent with those of earlier trials in which bimatoprost was more effective than latanoprost in lowering IOP at all time points and statistically superior in achieving low target pressures (DuBiner et al 2001; Gandolfi et al 2001). More recent studies also suggest a trend for greater efficacy of bimatoprost over latanoprost (Waters et al 2004; Simmons et al 2004; Konastas et al 2005).

The IOP lowering efficacy of latanoprost was compared with that of bimatoprost and travoprost in a large scale 12week clinical study by Parrish and colleagues (2003). There were no significant among-group differences in mean IOP, but it was concluded that all were potent IOP-lowering treatments. A more recent study reported that both bimatoprost and travoprost provided significant mean IOP reductions from baseline after 6 months of therapy in patients with glaucoma or OHT. Bimatoprost provided greater mean reductions and more patients achieved low target pressures (Cantor 2001). Bimatoprost has also been shown to be as effective as travoprost in black patients (Noecker, Earl, et al 2003).

Bimatoprost has also been shown to be an effective replacement therapy. Patients with open-angle glaucoma or OHT inadequately controlled by topical beta-blocker monotherapy were evaluated in an open-label, 12-week study and were more likely to achieve low target pressures with bimatoprost during both follow-up visit. Bimatoprost reduced IOP $4.5 \mathrm{~mm} \mathrm{Hg}(21.5 \%$; $<0.001)$ from baseline at week 6 and $4.2 \mathrm{~mm} \mathrm{Hg}(19.6 \% ; \mathrm{p}<0.001)$ at week 12 (Quinones and Earl 2004).

Bimatoprost has been proven to be safe and well tolerated (Cantor 2001; DuBiner et al 2001; Gandolfi et al 2001; Orengo-Nania et al 2001; Sherwood and Brandt 2001; Higginbotham et al 2002; Noecker, Dirks, et al 2003). The most common reported side effects of bimatoprost therapy are trace or mild hyperemia and eyelash growth (Sherwood and Brandt 2001; Higginbotham et al 2002; Abelson et al 2003). A 3-month comparison trial of bimatoprost and latanoprost reported both study medications were well tolerated. Mild conjunctival hyperemia and eyelash growth occurred more often with bimatoprost, while headache was 
more commonly reported with latanoprost (Gandolfi et al 2001). Bimatoprost is associated with a low incidence of increased iris pigmentation, $1.5 \%$ of patients after 1 year of treatment (Higginbotham et al 2002), and some patients may experience increased pigmentation of the eyelashes and periorbital tissue. Furthermore, a two-year study with bimatoprost reported an excellent safety profile with no reports of increased iris pigmentation, and no reports of uveitis or cystoid macular edema (CME) (Cohen et al 2004). As with latanoprost, bimatoprost may be associated with the development of CME in high-risk patients (Wand and Gaudio 2002). There has also been a case report of herpes simplex virus keratitis reactivation in a patient treated with bimatoprost for 1 month. Although a causal relationship was not proven, bimatoprost should be used with caution in patients with a history of herpes simplex virus keratitis (Kroll and Schuman 2002).

\section{Fixed combinations Dorzolamid-timolol fixed combination}

The fixed combination of dorzolamide (a sulfonamide and CAI) and timolol (a nonselective beta-blocker) has been marketed in recent years as the brand-name drug Cosopt ${ }^{\circledR}$. The fixed combination provides IOP lowering superior to that provided by monotherapy with either of its components but somewhat less than the concomitant administration of those components (prescribing information). Mean IOP reduction with the combination therapy has been reported to range from $1.5 \mathrm{~mm} \mathrm{Hg}$ to $4.2 \mathrm{~mm} \mathrm{Hg}$ at trough drug effect and from $4.9 \mathrm{~mm} \mathrm{Hg}$ to $5.4 \mathrm{~mm} \mathrm{Hg}$ at peak (Bacharach et al 2003; Solish et al 2004). The most commonly reported ocular adverse events are burning and stinging, but the potential for the serious systemic side effects (eg cardiovascular effects) exist because of the beta-blocker component (Clineschmidt et al 1998).

\section{Travoprost-timolol fixed combination}

Two 3-month studies comparing the concomitant use of travoprost $0.004 \%$ and timolol $0.5 \%$ with the fixed combination of travoprost/timolol reported comparable clinically relevant IOP reductions in patients with $\mathrm{OAG}$ and OHT. The fixed combination significantly lowered IOP by $7 \mathrm{~mm}$ to $9 \mathrm{~mm}$, similar to the IOP reductions observed with concomitant therapy. The most frequent ocular adverse event was hyperemia that occurred in $14.3 \%$ and $23.4 \%$ of patients treated with travoprost/timolol combination and concomitant travoprost-timolol, respectively (Hughes et al 2005;
Schuman et al 2005). When comparing the fixed combination to treatment with either travoprost or timolol alone in patients with OAG or OHT, two 3-month studies reported clinically relevant IOP reductions that were greater with fixed combination therapy than those produced by either travoprost or timolol alone (Barnebey et al 2005; Schuman et al 2005).

\section{Brimonidine-timolol fixed combination}

The fixed combination of brimonidine-timolol was well tolerated and provided significantly better IOP control when compared in a study with either brimonidine or timolol alone in patients with OAG or OHT. The mean decrease from baseline IOP ranged from $4.9 \mathrm{~mm} \mathrm{Hg}$ to $7.6 \mathrm{~mm} \mathrm{Hg}$ with brimonidine-timolol, from $3.1 \mathrm{~mm} \mathrm{Hg}$ to $5.5 \mathrm{~mm} \mathrm{Hg}$ with brimonidine, and from $4.3 \mathrm{~mm} \mathrm{Hg}$ to $6.2 \mathrm{~mm} \mathrm{Hg}$ with timolol. Mean IOP reductions from baseline were significantly larger with fixed brimonidine-timolol than with timolol at all follow-up measurements $(p \leq 0.026)$; the difference was greater than $1.5 \mathrm{~mm} \mathrm{Hg}$ at $10 \mathrm{AM}$, peak effect for each treatment. Mean IOP reductions from baseline were significantly larger with the fixed combination than with brimonidine at $8 \mathrm{AM}, 10 \mathrm{AM}$, and $3 \mathrm{PM}(\mathrm{p}<0.001)$; the difference was greater than $1.5 \mathrm{~mm} \mathrm{Hg}$ (Craven et al 2005).

Another 3-month study compared the fixed combination of brimonidine-timolol with the concomitant use of the components in 371 patients with OAG or OHT. During follow-up, the mean reduction from baseline IOP was significant $(\mathrm{p}<0.001)$ at all time points and ranged from $4.4 \mathrm{~mm} \mathrm{Hg}$ to $5.3 \mathrm{~mm} \mathrm{Hg}$ in each group. The fixed combination was as effective as concomitant therapy with respect to mean IOP and mean change from baseline IOP at all time points and visits. No significant between-group differences were found. Both treatments were well tolerated with no difference in adverse events between groups (Goni 2005).

\section{Latanoprost-timolol fixed combination}

The fixed combination of prostaglandin latanoprost $0.005 \%$ and the beta-blocker timolol $0.5 \%$ combines two mechanisms of action, latanoprost increases uveoscleral outflow whereas timolol decreases the formation of aqueous humor in the ciliary epithelium. Due to the mechanism of action of latanoprost, QD dosing of the fixed combination resulted in slightly greater additional IOP reduction compared with either drug administered separately. The fixed combination has a safety profile similar to that of its 
individual components, and provides a convenient alternative for the treatment of patients uncontrolled by monotherapy (Feldman 2004).

A 6-week study compared the fixed combination latanoprost-timolol, given once each evening, with the concomitant use of brimonidine and timolol, given BID, in patients with POAG and OHT. All patients were begun on timolol alone BID for 1 month prior to randomization. The study found that in 32 patients the IOP diurnal curve on timolol alone $(20.9 \pm 2.8 \mathrm{~mm} \mathrm{Hg})$ decreased to $17.9 \pm 3.2 \mathrm{~mm}$ $\mathrm{Hg}$ when patients were treated with latanoprost-timolol and to $19.0 \pm 2.4 \mathrm{~mm} \mathrm{Hg}$ when treated with brimonidine and timolol $(\mathrm{p}=0.02)$. Intraocular pressures at individiual timepoints were statistically similar between the groups at the $8 \mathrm{AM}$ trough and 2 and 4 hours after dosing. However, beyond 4 hours after dosing, the fixed combination-treated patients demonstrated a trend towards lower IOPs at each 2-hour time-point that was not statistically significant after a Bonferroni correction $(\mathrm{p} \leq 0.05)$. Reported side effects were similar between groups (Stewart et al 2003). A recent 6month study compared the fixed combination of latanoprosttimolol with concomitant use of brimonidine and timolol in 325 patients. At the 6 month visit, mean IOP was 16.9(standard deviation [SD] 2.8) $\mathrm{mm} \mathrm{Hg}$ in the fixed combination group and $18.2(\mathrm{SD} 3.1) \mathrm{mm} \mathrm{Hg}$ in the brimonidine-timolol group $(\mathrm{p}<0.001)$ (Garcia-Sanchez et al 2004).

Another comparison study between two fixed combinations, latanoprost-timolol and dorzolamidetimolol, found latanoprost-timolol slightly more effective than that of dorzolamide-timolol in reducing mean diurnal IOP. The mean difference was $1.00 \mathrm{~mm} \mathrm{Hg}(95 \%$ confidence interval, $0.31-1.69 ; \mathrm{p}=0.005)$ in favor of the latanoprosttimolol fixed combination. Both treatments were well tolerated (Shin et al 2004).

\section{Discussion}

The management of OAG and OHT will evolve as we gain knowledge of the pathophysiology of glaucoma. Today, however, the primary objective of any pharmacological treatment regimen for glaucoma is the preservation of the visual field through the early and aggressive reduction of IOP. To accomplish this objective, a target IOP should be identified, or upper limit IOP expected to slow or stop opticnerve damage. Although there is no single IOP above which a patient will always progress and below which a patient never will, a target $\leq 17 \mathrm{~mm} \mathrm{Hg}$ is likely to be low enough to preserve the visual field of most patients. Furthermore, because large diurnal fluctuations are a risk factor for glaucomatous progression, this target pressure must be controlled throughout the day.

With a target pressure in mind, the ultimate therapeutic selection should be the option that offers the greatest potential benefit when efficacy, side effect risk, quality of life, and cost are considered. An optimal agent is one that produces clinically significant reductions in IOP, allows patients to achieve target levels of IOP at which the progression of glaucomatous damage is halted and the visual field preserved, controls diurnal IOP fluctuations, has a favorable adverse event profile, is convenient to use with a dosing regimen patients are likely to follow, exposes patients to the least amount of BAK, and finally, presents the possibility for potential additional benefits beyond IOP control.

Topical beta-blockers have long been used to reduce IOP in patients with glaucoma or OHT, but their side effect profile may make them undesirable for use in many patients. Topical CAIs may not provide adequate IOP lowering in many patients and their more frequent dosing schedules may limit patient compliance. The equivocal potential of CAIs to enhance ocular blood flow may provide an added benefit.

Brimonidine, a highly selective alpha ${ }_{2}$ adrenergic agonist, has proven highly effective as monotherapy, adjunctive therapy, and replacement therapy for lowering IOP in patients with glaucoma and OHT. The efficacy of brimonidine has been shown to be sustained for over 4 years in a clinical trial. The recent introduction of brimonidine $\mathrm{P}$ $0.1 \%$ provides clinicians another treatment option for effective IOP-lowering. This new formulation contains $50 \%$ less active ingredient than the original brimonidine $0.2 \%$ formulation, but continues to provide equivalent efficacy.

Brimonidine as monotherapy provides IOP lowering comparable with that provided by nonselective beta-blockers and is superior to topical CAIs, and selective beta-blockers. Brimonidine has provided significant IOP reductions when used adjunctively to topical beta-blockers and when used as a dual regimen with the prostaglandin prodrug latanoprost. Brimonidine is most often dosed BID and provides a convenient dosing schedule. Brimonidine is safe and effective, with the most commonly reported side effect being ocular allergy.

Latanoprost, a prostaglandin prodrug, has been proven in numerous clinical trials to be an effective IOP-lowering agent, but several studies have reported that a significant percentage of patients fail to respond to latanoprost therapy 
(Scherer 2002; Noecker, Dirks, et al 2003 ). Latanoprost is dosed QD and provides a convenient dosing schedule. Compared with bimatoprost, latanoprost may have a greater incidence of intraocular adverse events (CME, iris pigmentation changes, uveitis) whereas adverse events associated with bimatoprost are most often extraocular, (eg, hyperemia and itching).

Unoprostone, which is dosed BID, has been shown to be less efficacious than latanoprost, although, additional studies are needed to determine the true IOP-lowering efficacy of this drug in a non-Japanese population. The use of unoprostone has been associated with several potentially serious adverse events, including corneal epithelial defects. Unoprostone may possibly potentially provide a potentially added benefit of ET-1 effects, but further study is needed.

Travoprost, a prostaglandin, appears to provide IOPlowering comparable with that provided by latanoprost. There is evidence that travoprost may be more effective in black patients than in white patients. The most commonly reported adverse event with travoprost is conjunctival hyperemia.

The prostamide bimatoprost allows many patients to achieve the low target pressures most likely to preserve the visual field. The most common side effect of bimatoprost therapy is conjunctival hyperemia. Bimatoprost provides low, stable IOP throughout the day and night, and the efficacy is sustained with long-term use. Bimatoprost is very effective in both monotherapy and adjunctive therapy. The most common side effect with bimatoprost therapy is mild conjunctival hyperemia.

The various fixed combinations of timolol with dorzolamide, travoprost, brimonidine, and latanoprost have been shown to provide clinically relevant IOP-lowering in a more convenient form than the concomitant administration of its components. Fixed combinations offer benefits of cost, convenience, and safety, but limit individualization of dosing (Fechtner and Realini 2004).

\section{Conclusions}

Based on the data available today, glaucoma is a disease of significant morbidity, but one that can be effectively prevented and/or treated in many patients. With the variety of pharmacologic agents and classes available, physicians have more options for IOP-lowering than ever before. Effective treatment calls for the selection of IOP-lowering agents that will allow each patient to safely achieve a target pressure at which their visual field is preserved, while maximizing patient convenience and comfort, and providing the potential for additional benefits such as neuroprotection.

\section{References}

Abelson MB, Mroz M, Rosner SA, et al. 2003. Multicenter, open-label evaluation of hyperemia associated with use of bimatoprost in adults with open-angle glaucoma or ocular hypertension. Adv Ther, 20:113.

Acheampong AA, Small D, Baumgarten V, et al. 2002. Formulation effects on ocular absorption of brimonidine in rabbit eyes. J Ocul Pharmacol Ther, 18:325-37. Erratum in: J Ocul Pharmacol Ther, 19:91.

Akman A, Cetinkaya A, Akova YA, et al. 2005. Comparison of additional intraocular pressure-lowering effects of latanoporast vs brimonidine in primary open-angle glaucoma patients with intraocular pressure uncontrolled by timolol-dorzolamide combination. Eye, 19:145-51.

Alm A, Schoenfelder J, McDermott J. 2004. A 5-year, multicenter, openlabel, safety study of adjunctive latanoprost therapy for glaucoma. Arch Ophthalmol, 122:957-65.

Alm A, Widengard I, Kjellgren D, et al. 1995. Latanoprost administered once daily caused a maintained reduction of intraocular pressure in glaucoma patients treated concomitantly with timolol. $\mathrm{Br} J$ Ophthalmol, 79:12-16.

[AAO] American Academy of Ophthalmology. 2000. Preferred Practice Pattern ${ }^{\mathrm{TM}}$ : primary open-angle glaucoma. AAO, San Francisco, CA, USA.

Arend O, Harris A, Arend S, et al. 1998. The acute effect of topical betaadrenoreceptor blocking agents on retinal and optic nerve head circulation. Acta Ophthalmol Scand, 76:43-49.

Azuma I, Masuda K, Kitazawa Y, et al. 1993. Double-masked comparative study of UF-021 and timolol ophthalmic solutions in patients with primary open-angle glaucoma or ocular hypertension. Jpn $J$ Ophthalmol, 37:514-25.

Bacharach J, Delgado MF, Iwach AG. 2003. Comparison of the efficacy of the fixed-combination timolol/dorzolamide versus concomitant administration of timolol and dorzolamide. J Ocul Pharmacol Ther, 19:93-6.

Barnebey HS, Orengo-Nania S, Flowers BE, et al. 2005. The safety and efficacy of travoprost $0.004 \% /$ timolol $0.05 \%$ fixed combination ophthalmic solution. Am J Ophthalmol, 140:1-7.

Bartlett JD, Olivier M, Richardson T, et al. 2001. Central nervous system and plasma lipid profiles associated with carteolol and timolol in postmenopausal black women. J Glaucoma, 8:388-95.

Berdy GJ, Abelson MB, Smith LM, et al. 1992. Preservative-free artifical tear preparations. Assessment of corneal epithelial toxic effects. Arch Ophthalmol, 110:528-32.

Brandt JD, Vandenburgh AM, Chen K, et al. 2001. Comparison of onceor twice-daily bimatoprost with twice-daily timolol in patients with elevated IOP: A 3-month clinical trial. Ophthalmology, 108:1023-31.

Brubaker RF. 2001. Mechanism of action of bimatoprost (Lumigan). Surv Ophthalmol, 45(Suppl 4):S347-51.

Camras CB, Alm A, Watson P, et al. 1996. Latanoprost, a prostaglandin analog, for glaucoma therapy: efficacy and safety after 1 year of treatment in 198 patients. Ophthalmology, 103:1916-24.

Camras CB; The United States Latanoprost Study Group. 1996. Comparison of latanoprost and timolol in patients with ocular hypertension and glaucoma. A six-month, masked, multicenter trial in the United States. Ophthalmology, 103:138-47.

Cantor LB. 2001. Bimatoprost: a member of a new class of agents, the prostamides, for glaucoma management. Expert Opin Investig Drugs, 10:721-31.

Chiba T, Kashiwagi K, Ishiiima K, et al. 2004. A prospective study of iridial pigmentation and eyelash changes due to ophthalmic treatment with latanoprost. Jpn J Ophthalmol, 48:141-7. 
Chiba T, Kashiwagi, Chiba N, et al. 2003. Comparison of iridial pigmentation between latanoprost and isopropyl unoprostone: a long term prospective comparative study. Br J Ophthalmol, 87:956-9.

Clineschmidt CM, Williams RD, Snyder E, et al. 1998. A randomized trial in patients inadequately controlled with timolol alone comparing the dorzolamide-timolol combination to monotherapy with timolol or dorzolamide. Ophthalmology, 105:1952-9.

Cohen JS, Gross RL, Cheetham HK, et al. 2004. Two-year double-masked comparison of bimatoprost with timolol in patients with glaucoma or ocular hypertension. Surv Ophthalmol, 49(Suppl 1):S45-52.

Coleman AL, Lerner F, Bernstein P, et al. 2003. A 3-month randomized controlled trial of bimatoprost $\left(\right.$ Lumigan $\left.^{\circledR}\right)$ versus combined timolol and dorzolamide $\left(\mathrm{Cosopt}^{\mathbb{1}}\right)$ in patients with glaucoma or ocular hypertension. Ophthalmology, 110:2362-8.

Coons SJ, Sheahan SL, Martin SS, et al. 1994. Predictors of medication noncompliance in a sample of older adults. Clin Ther. 16:110-17.

Craven ER, Walters TR, Williams R, et al. 2005. Brimonidine and timolol fixed-combination therapy versus monotherapy: a 3-month randomized trial in patients with glaucoma or ocular hypertension. $J$ Ocul Pharmacol Ther, 21:337-48.

De Saint Jean M, Brignole P, Bringuier AF, et al. 1999. Effects of benzalkonium chloride on growth and survival of Chang conjunctival cells. Invest Ophthalmol Vis Sci, 40:619-30.

De Saint Jean M, Debbasch C, Brignole F, et al. 2000. Toxicity of preserved and unpreserved antiglaucoma topical drugs in an in vitro model of conjunctival cells. Curr Eye Res, 20:85-94.

Debbasch C, Rat P, Warnet JM. 2000. Evaluation of the toxicity of benzalkonium chloride on the ocular surface. $J$ Toxicol Cutaneous Ocul Toxicol, 19:105-15.

Dong JQ, Babusis DM, Welty DF, et al. 2004. Effects of the preservative purite on the bioavailability of brimonidine in the aqueous humor of rabbits. J Ocul Pharmacol Ther, 20:285-92.

DuBiner H, Cooke D, Dirks M, et al. 2001. Efficacy and safety of bimatoprost in patients with elevated IOP: A 30-day comparison with latanoprost. Surv Ophthalmol, 45(Suppl 4):S353-60.

[EDGED] Joint National Task Force for the Early Detection of Glaucomatous Eye Disease. 2002. NCQA Concept Document. June.

Fechtner RD, Khouri AS, Zimmerman TJ, et al. 1998 Anterior uveitis associated with latanoprost. Am J Ophthalmology, 126:37-41.

Fechtner RD, Realini T. 2004. Fixed combinations of topical glaucoma medications. Curr Opin Ophthalmol, 15:132-5.

Feldman RM. 2004. An evaluation of the fixed-combination of latanoprost and timolol for use in open-angle glaucoma and ocular hypertension. Expert Opin Pharmacother, 5:909-21.

Fraunfelder FT. 1980. Interim report: national registry of possible druginduced ocular side effects. Ophthalmology, 87:87-90.

Gandolfi S, Simmons ST, Sturm R, et al; Bimatoprost Study Group 3. 2001. Three-month comparison of bimatoprost and latanoprost in patients with glaucoma and ocular hypertension. Adv Ther, 18:110-21.

Garcia-Sanchez J, Rouland JE, Spiegel D, et al. 2004. A comparison of the fixed combination of latanoprost and timolol with the unfixed combination of brimonidine and timolol in patients with elvevated intraocular pressure. A six month, evaluator masked, multicentre study in Europe. Br J Ophthalmol, 88:877-83.

Gasset AR, Ishii Y, Kaufman HE, et al. 1974. Cytotoxicity of ophthalmic preservatives. Am J Ophthalmol, 78:98-105.

Goh Y, Kishino J. 1994. Pharmacological characterization of prostaglandinrelated ocular hypotensive agents. Jpn J Ophthalmol, 38:236-45.

Goni FJ; Brimonidine/Timolol Fixed Combination Study Group. 2005. 12-week study comparing the fixed combination of brimonidine and timolol with concomitant use of the individual components in patients with glaucoma and ocular hypertension. Eur J Ophthalmol, 15:58190 .

Gordon MO, Beiser JA, Brandt JD, et al. 2002. The Ocular Hypertension Treatment Study: baseline factors that predict the onset of primary openangle glaucoma. Arch Ophthalmol, 120:714-20; discussion 829-30.
Grant R, Ajello M, Vlass E. 1996. Salt water or high tech? A look at two new rinsing solutions for contact lenses. Optician, 212:38-41.

Grant WM, Schuman JS. 1990. Toxicology of the eye. 4th ed. Springfield, IL: CC Thomas, p 208-13.

Harris A, Arend O, Chung HS, et al. 2000. A comparative study of betaxolol and dorzolomide effect on ocular circulation in normal-tension glaucoma patients. Ophthalmology, 107:430-4.

Higginbotham EJ, Schuman JS, Goldberg I, et al. 2002. One-year, randomized study comparing bimatoprost and timolol in glaucoma and ocular hypertension. Arch Ophthalmol, 120:1286-93.

Hommer A, Kapik B, Shams N, et al. 2003. Unoprostone as adjunctive therapy to timolol: a double masked randomised study versus brimonidine and dorzolamide. Br J Ophthalmol, 87:592-8.

Hoyng PF, van Beek LM. 2000. Pharmacological therapy for glaucoma: a review. Drugs, 59:411-34.

Hughes BA, Bacharach J, Craven ER, et al. 2005. A three-month, multicenter, double-masked study of the safety and efficacy of travoprost $0.004 \% /$ timolol $0.5 \%$ ophthalmic solution compared with travoprost $0.004 \%$ ophthalmic solution and timolol $0.5 \%$ dosed concomitantly in subjects with open angle glaucoma or ocular hypertension. J Glaucoma, 14:392-9.

Javitt J, Goldberg I; Brimonidine Outcomes Study Group II. 2000. Comparison of clinical success rates and quality of life effects of brimonidine tartrate $0.2 \%$ and betaxolol $0.25 \%$ suspension in patients with open-angle glaucoma and ocular hypertension. J Glaucoma, 9:398-408

Johnstone MA. 1997. Hypertrichosis and increased pigmentation of eyelashes and increased pigmentation of eyelashes and adjacent hair in the region of the ipsilateral eyelids of patients treated with unilateral topical latanoprost. Am J Ophthalmol, 124:544-7.

Jonas JB, Martus P, Horn FK, et al. 2004. Predictive factors of the optic nerve head for development or progression of glaucomatous visual field loss. Invest Ophthalmol Vis Sci, 45:2613-18.

Kass MA, Heuer DK, Higginbotham EJ, et al. 2002. The ocular hypertension treatment study: a randomized trial determines that topical ocular hypotensive medication delays or prevents the onset of primary open-angle glaucoma. Arch Ophthalmol, 120:701-13.

Katz JL; Brimonidine Study Group. 1999. Brimonidine tartrate $0.2 \%$ twice daily vs timolol $0.5 \%$ twice daily: 1 -year results in glaucoma patients. Am J Ophthalmol, 127:20-6.

Katz JL; Brimonidine-purite Study Groups 1 and 2. 2002. Twelve-month evaluation of brimonidine-purite versus brimonidine in patients with glaucoma or ocular hypertension. J Glaucoma, 1:119-26.

Kent AR, Nussdorf JD, David R, et al. 2001. Vitreous concentration of topically applied brimonidine tartrate $0.2 \%$. Ophthalmology, 108:784-7.

Kitnarong N, Zhao Y, Netland PA, et al. 2004. Efficacy of latanoprost and timolol maleate in black and white patients. Adv Ther, 21:203-13.

Konstas AG, Katsimbris JM, Lallos N, et al. 2005. Latanoprost $0.005 \%$ versus bimatoprost $0.03 \%$ in primary open-angle glaucoma. Ophthalmology, 112:262-6.

Kroese M, Burton H. 2003. Primary open angle glaucoma. The need for a consensus case definition. J Epidemiol Community Health, 57:752-4.

Kroll DM, Schuman JS. 2002. Reactivation of herpes simplex virus keratitis after initiating bimatoprost treatment for glaucoma. Am J Ophthalmol, 133:401-3.

LeBlanc RP. 1998. 12-month results of an ongoing randomized trial comparing brimonidine tartrate $0.2 \%$ and timolol $0.5 \%$ given twice daily in glaucoma or ocular hypertension. Ophthalmology, 105:1960-7.

Lee DA, Gornbein J, Abrams C. 2000. The effectiveness and safety of brimonidine as mono-, combination, or replacement therapy for patients with primary open-angle glaucoma or ocular hypertension: a post hoc analysis of an open-label community trial. JOcul Pharmacol Ther, 16:3-18.

Lee DA; Glaucoma Trial Study Group. 2000. Efficacy of brimonidine as replacement therapy in patients with open-angle glaucoma or ocular hypertension. Clin Ther, 22:53-65. 
Martus P, Stroux A, Budde WM, et al. 2005. Predictive factors for progressive optic nerve damage in various types of chronic openangle glaucoma. Am J Ophthalmol, 139:999-1009.

Masschelein WJ. 1979. Chlorine dioxide, chemistry and environmental impact of oxychlorine compounds. Ann Arbor, MI: Ann Arbor Sci.

McMahon CD, Shaffer RN, Hoskins HD Jr, et al. 1979. Adverse effects experienced by patients taking timolol. Am J Ophthalmol, 88:736-8.

Mishima HK, Masuda K, Kitazawa Y, et al. 1996. A comparison of latanoprost and timolol in primary open-angle glaucoma and ocular hypertension: a 12-week study. Arch Ophthalmol, 114:929-32.

Morales J, Shihab ZM, Brown SM, et al. 2001. Herpes simplex virus dermatitis in patients using latanoprost. Am J Ophthalmol, 132:114-16.

Nelson WL, Fraunfelder FT, Sills JM, et al. 1986. Adverse respiratory and cardiovascular events attributed to timolol ophthalmic solution, 1978-1985. Am J Ophthalmol, 102:606-11.

Netland PA, Landry T, Sullivan EK, et al. 2001. Travoprost compared with latanoprost and timolol in patients with open-angle glaucoma or ocular hypertension. Am J Ophthalmol, 132:472-84.

Noecker RJ, Dirks MS, Choplin NT, et al. 2003. A six-month randomized clinical trial comparing the intraocular pressure-lowering efficacy of bimatoprost and latanoprost in patients with ocular hypertension or glaucoma. Am J Ophthalmol, 135:55-63.

Noecker RJ, Earl ML, Mundorf T, et al. 2003. Bimatoprost $0.03 \%$ versus travoprost $0.004 \%$ in black Americans with glaucoma or ocular hypertension. Adv Ther, 20:121-8.

Nordmann J, Mertz B, Yannoulis N, et al. 2002. A double-masked randomized comparison of the efficacy and safety of unoprostone with timolol and betaxolol in patients with primary open-angle glaucoma including pseudoexfoliation glaucoma or ocular hypertension: 6 month data. Am J Ophthalmol, 133:1-10.

Orengo-Nania S, Landry T, Von Tress M, et al. 2001. Evaluation of travoprost as adjunctive therapy in patients with uncontrolled intraocular pressure while using timolol $0.5 \%$. Am J Ophthalmol, 132:860-8.

Osborne NN, Ugarte M, Chao M, et al. 1999. Neuroprotection in relation to retinal ischemia and relevance to glaucoma. Surv Ophthalmol, 43:S102-28.

Osborne NN, Wood JP, Chidlow G. 2005. Invited review: neuroprotective properties of certain beta-adrenoceptor antagonists used for the treatment of glacucoma. J Ocul Pharmacol Ther, 21:175-81.

Ozturk F, Ermiss SS, Inan UU, et al. 2005. Comparison of the efficacy and safety of dorzolamide $2 \%$ when added to brimonidine $0.2 \%$ or timolol maleate $0.5 \%$ in patients with primary open-angle glaucoma. J Ocul Pharmacol Ther, 21:68-74.

Parrish RK, Palmberg P, Sheu WP, et al. 2003. A comparison of latanoprost, bimatoprost, and travoprost in patients with elevated intraocular pressure: a 12-week, randomized, masked-evaluator multicenter study. Am J Ophthalmol, 135:688-703.

Patel SC, Spaeth GL. 1995. Compliance in patients prescribed eyedrops for glaucoma. Ophthalmic Surg, 26:233-6.

Pissella PJ, Fillacier K, Elena PP, et al. 2000. Comparison of the effects of preserved and unpreserved formulations of timolol on the ocular surface of albino rabbits. Ophthalmic Res, 32:3-8.

Polska E, Doelemeyer A, Luksch A, et al. 2002. Partial antagonism of endothelin 1-induced vasoconstriction in the human choroid by topical unoprostone isopropyl. Arch Ophthalmol, 120:348-52.

Przydryga JT, Egloff C; Swiss Start Study Group. 2004. Intraocular pressure lowering efficacy of travoprost. Eur J Ophthalmol, 14:416-22.

Quigley HA, Vitale S. 1997. Models of glaucoma prevalence and incidence in the United States. Invest Ophthalmol Vis Sci, 38:83-91.

Quinones R, Earl ML. 2004. The efficacy of bimatoprost $0.03 \%$ montherapy in patients previously using topical beta-blocker monotherapy for the treatment of glaucoma or ocular hypertension. Adv Ther, 21:370-9.

Rozen S, Abelson M, Giovanoni A, et al. 1998. Assessment of the comfort and tolerance of $0.5 \%$ carboxymethylcellulose preserved with purite (Refresh Tears) in dry eye sufferers [Abstract]. Invest Ophthalmol Vis Sci, 39:B343.
Sakurai M, Araie M, Oshika T, et al. Effects of topical application of UF021, a novel prostaglandin-related compound, on aqueous humor dynamics in rabbit. Jpn J Ophthalmol, 1993, 37:252-8.

Scherer WJ. 2002. A retrospective review of non-responders to latanoprost. J Ocul Pharmacol Ther, 18:287-91

Schuman JS, Horwitz B, Choplin NT, et al; Chronic Brimonidine Study Group. 1997. A one-year study of brimonidine twice-daily in glaucoma and ocular hypertension. A controlled, randomized, multicenter clinical trial. Arch Ophthalmol, 115:847-52.

Schuman JS, Katz GJ, Lewis RA, et al. 2005. Efficacy and safety of a fixed combination of travoprost $0.004 \% /$ timolol $0.05 \%$ ophthalmic solution once daily for open-angle glaucoma of ocular hypertension. Am J Ophthalmol, 140:242-50.

Schuman JS. 1996. Clinical experience with brimonidine $0.2 \%$ and timolob $0.5 \%$ in glaucoma and ocular hypertension. Surv Ophthalmol, 41(Suppl 1):S27-37.

Schuman JS; Brimonidine Study Groups 1 and 2. 2000. Effects of systemic beta-blocker therapy on the efficacy and safety of topical brimonidine and timolol. Ophthalmology, 107:1171-7.

Serle JB; Brimonidine Study Group III. 1996. A comparison of the safety and efficacy of twice daily brimonidine $0.2 \%$ versus betaxolol $0.25 \%$ in subjects with elevated intraocular pressure. Surv Ophthalmol, 41(Suppl 1):S39-47.

Sherwood M, Brandt J; Bimatoprost Study Groups 1 and 2. 2001. 6-month comparison of bimatoprost once-daily and twice-daily with timolol twice-daily in patients with elevated IOP. Surv Ophthalmol, 45(Suppl 4):S361-8.

Shin DH, Feldman RM, Sheu WP; Fixed Combination Latanoprost/Timolol Study Group. 2004. Efficacy and safety of the fixed combination latanoprost/timolol versus dorzolamide/timolol in patients with elevated intraocular pressure. Ophthalmology, 111:276-82.

Sihota R, Saxena R, Agarwal HC, et al. 2004. Crossover comparison of timolol and latanoprost in chronic primary angle-closure glaucoma. Arch Ophthalmol, 122:185-9.

Sihota R, Saxena R, Agarwal HC, et al. 2003. Peak pressures: crossover study of timolol and latanoprost. Eur J Ophthalmol, 13:546-52.

Silver LH; Brinzolamide Primary Therapy Study Group. 1998. Clinical efficacy and safety of brinzolamide (Azopt), a new topical carbonic anhydrase inhibitor for primary open-angle glaucoma and ocular hypertension. Am J Ophthalmol, 126:400-8.

Simmons S, Samuelson T; Alphagan/Xalatan Study Group. 2000. Comparison of brimonidine with latanoprost in the adjunctive treatment of glaucoma: Clin Ther, 22:388-99.

Simmons ST, Dirks MS, Noecker RJ. 2004. Bimatoprost versus latanoprost in lowering intraocular pressure in glaucoma and ocular hypertension: results from parallel-group comparison trials. Adv Ther, 21:247-62.

Simmons ST, Earl ML; Alphagan/Xalatan Study Group. 2002. 3-Month Comparison of brimonidine and latanoprost as adjunctive therapy in glaucoma and ocular hypertension patients uncontrolled on $\beta$ blockers: Tolerability and peak IOP lowering. Ophthalmology, 109:307-15.

Simmons ST; Trusopt/Alphagan Study Group. 2001. Efficacy of brimonidine $0.2 \%$ and dorzolamide $2 \%$ as adjunctive therapy to betablockers in adult patients with glaucoma or ocular hypertension. Clin Ther, 23:604-19.

Solish AM, DeLucca PT, Cassel DA, et al. 2004. Dorzolamide/Timolol fixed combination versus concomitant administration of brimonidine and timolol in patients with elevated intraocular pressure: a 3-month comparison of efficacy, tolerability, and patient-reported measures. $J$ Glaucoma, 13:149-57.

Stewart WC, Stewart JA, Day D, et al. 2003. Efficacy and safety of timolol maleate/latanoprost fixed combination versus timolol maleate and brimonidine given twice daily. Acta Ophthalmol Scand, 81:242-6.

Taniguchi T, Haque MS, Sugiyama K, et al. 1996. Ocular hypotensive mechanism of topical isopropyl unoprostone, a novel prostaglandin metabolite-related drug, in rabbits. J Ocul Pharmacol Ther, 12:489-98.

Thylefors, B, Négrel AD. 1994. The global impact of glaucoma. Bull World Health Org, 72:323-6. 
Toor A, Chanis RA, Polikoff LA, et al. 2005. Additivity of pilocarpine to bimatoprost in oculary hypertension and early glaucoma. J Glaucoma, $14: 243-8$.

Toris CB, Alm A, Camras CB. 2002. Latanoprost and cholinergic agonists in combination. Surv Ophthalmol, 47(Suppl 1):S141-7.

Toris CB, Camras CB, Yablonski ME. 1993. Effects of PhXA41, a new prostaglandin $\mathrm{F} 2$ analog, on aqueous humor dynamics in human eyes. Ophthalmology, 100:1297-304.

Tsukamoto H, Noma H, Matsuvama S, et al. 2005. The efficacy and safety of topical brinzolamide and dorzolamide when added to the combination therapy of latanoprost and a beta-blocker in patients with glaucoma. J Ocul Pharmacol Ther, 21:170-3.

Turacli ME, Ozden RG, Gurses MA. 1998. The effect of Betaxolol on ocular blood flow and visual fields in patients with normotension glaucoma. Eur J Ophthalmol, 8:62-6.

Valuck RJ, Perlman JI, Anderson C, et al. 2001. Co-prescribing of medications used to treat obstructive lung disease, congestive heart failure and depression among users of topical beta-blockers: estimates from three US Veterans Affairs Medical Centers. Pharmacoepidemiol Drug Saf, 10:511-16.

Van Buskirk EM. 1980. Adverse reactions from timolol administration. Ophthalmology, 87:447-50.

Varma R, Ying-Lai M, Francis BA, et al. 2004. Prevalence of open-angle glaucoma and ocular hypertension in Latinos: the Los Angeles Latino Eye Study. Ophthalmology, 111:1439-48.

Velde TM, Kaiser FE. 1983. Ophthalmic timolol treatment causing altered hypoglycemic response in a diabetic patient. Arch Internal Med, 143:1627.

Walters TR, DuBiner HB, Carpenter S, et al. 2004. 24-Hour IOP control with once-daily bimatoprost, timolol gel-forming solution, or latanoprost: a 1-month, randomized, comparative clinical trial. Surv Ophthalmol, 49:S26-35.

Walters TR, Shapiro AM, Chapin MJ. 2000. A comparison of the efficacy, safety, and quality of life of brimonidine with latanoprost vs. latanoprost and timolol. Invest Ophthalmol Vis Sci, 41(Suppl 4):S514.

Wand M, Gaudio AR. 2002. Cystoid macular edema associated with ocular hypotensive lipids. Am J Ophthalmol, 133:403-5.
Wand M, Gilbert CM, Liesegang TJ. 1999. Latanoprost and herpes simplex keratitis. Am J Ophthalmol, 127:602-4.

Warwar RE, Bullock JD, Ballal D. 1998. Cystoid macular edema and anterior uveitis associated with latanoprost use: experience and incidence in a retrospective review of 94 patients. Ophthalmology, 105:263-8.

Watson P, Stjernschanz J; Latanoprost Study Group. 1996. A six-month randomized double-masked study comparing latanoprost to timolol in open-angle glaucoma and ocular hypertension. Ophthalmology, 103:126-37.

Wayman L, Larsson LI, Maus T, et al. 1997. Comparison of dorzolamide and timolol as suppressors of aqueous humor flow in humans. Arch Ophthalmol, 115:1368-71.

Wheeler LA, Gil DW, WoldeMussie E. 2001. Role of alpha-2 adrenergic receptors in neuroprotection and glaucoma. Surv Ophthalmol, 45(Suppl 3):S290-94.

Wheeler LA, WoldeMussie E, Lai R. 2003. Role of alpha 2-agonists in neuroprotection. Surv Ophthalmol, 48(Suppl 1):S47-51.

WoldeMussie E, Ruiz G, Wijono M, et al. 2001. Neuroprotection of retinal ganglion cells by brimonidine in rats with laser-induced chronic ocular hypertension. Ophthalmol Vis Sci, 42:2849-55.

Yamamoto T, Kitazawa Y, Azuma I, et al. 1997. Clinical evaluation of UF-021 (Rescula isopropyl unoprostone). Surv Ophthalmol, 41(Suppl 2):S99-103.

Yarangumeli A, Kural G. 2004. Are there any benefits of Betoptic S (betaxolol $\mathrm{HCl}$ ophthalmic suspension) over other beta-blockers in the treatment of glaucoma? Expert Opin Pharmacother, 5:1071-81.

Yoles E, Wheeler L, Schwartz M. 1999. Alpha2-adrenoceptor agonists are neuroprotective in a rat model of optic nerve degeneration. Invest Ophthalmol Vis Sci, 40:65-73.

Zabriskie NA, Ahmed IK, Cantor LB, et al. 2000. Safety and efficacy of combination therapy with brimonidine $0.2 \%$ and latanoprost $0.005 \%$ versus fixed timolol $0.5 \%$ /dorzolamide $2 \%$ in patients with glaucoma or ocular hypertension. Invest Ophthalmol Vis Sci, 41(Suppl 4):S833.

Zimmerman T. 2000. Medicinal therapy for glaucoma. In: Eid TM, Spaeth GL, (eds). The glaucomas: concepts and fundamentals. Philadelphia: Lippincott Williams and Wilkins. p 27-45. 
